\section{What can shipwreck glasses reveal about the durability of vitrified nuclear waste?}

\section{CLARE L THORPE AND CLAIRE L CORKHILL}

University of Sheffield

Presenting Author: clare.thorpe@sheffield.ac.uk

Understanding the long-term durability of vitrified radioactive waste is of high national and international priority as the UK, and other countries, pursue a safe solution for radioactive waste disposal. Alkali-borosilicate glasses, those most commonly used to immobilise radioactive material, have been manufactured for little over 100 years, therefore, to assess their long-term durability, we must rely on accelerated laboratory testing, or on studying other silicate glass compositions that have been in existence over much longer time periods. Glass dissolution, when contacted by water or water vapour, is the primary mechanism of glass alteration [1], however, the majority of studies have been carried out in simple solutions (e.g. Ultra-pure water) and under sterile laboratory conditions. The effects of complex and dynamic solution chemistry, biology and biological processes on glass dissolution are, as yet, poorly understood.

Interactions between glass and fungi, plants and microorganisms have been documented since the nineteenth century from the point of view of preservation of ancient artefacts, stained glass windows and optical instruments [e.g. 2,3]. Similarly, bacterial alteration of glassy material has been studied from the point of view of mineral weathering (e.g. Fe release from basaltic lava flows) [4].

Here, chemical and biological alteration and associated secondary (bio)mineralisation were observed on 265-year-old glass glasses from a marine environment. Alteration is compared with that observed in accelerated laboratory tests using high temperatures $\left(90^{\circ} \mathrm{C}\right)$ and synthetic seawater. Glasses are from the shipwreck of the Albion, a sailing vessel that sank on route to China with a cargo of glass ingots in 1765 (recovered 1985). Glasses are lead-silicates coloured with heavy metals, blue (cobalt), green (copper), and clear (manganese) and show evidence of preferential biological colonisation, dependent on glass chemistry, and enhanced corrosion were organisms are present in addition to glass alteration layers formed by chemical dissolution (Figure 1).

Gin et al., (2013), Materials Today, 16(6), 243-248.

Drewello \& Weissmann, (1997), Applied Microbiology and Biotechnology, 47(4), 337-346.

Krumbein, Urzì, and Gehrmann (1991), Geomicrobiology Journal, 9(2-3), 139-160.

Stranghoener et al., (2018). Frontiers in Microbiology, 9, 1252 .

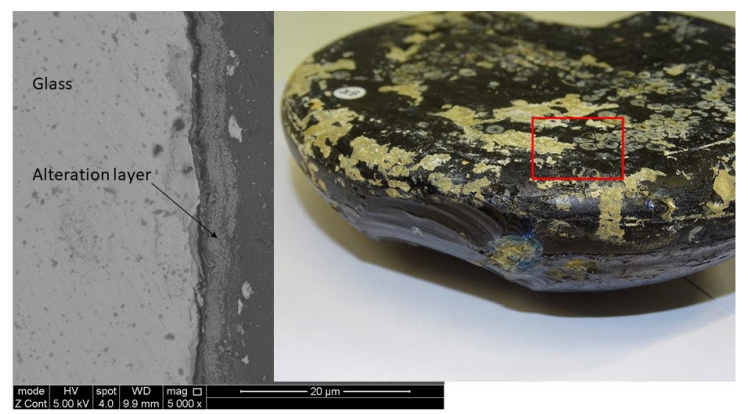

